\title{
Predicting critical illness mortality and personalizing therapy: moving to multi- dimensional data
}

\author{
Zudin A. Puthucheary ${ }^{1,2^{*}}$ and Paul Wischmeyer ${ }^{3,4}$ \\ See related research by Looijaard et al., http://ccforum.biomedcentral.com/articles/10.1186/s13054-016-1563-3.
}

Keywords: Skeletal muscle, Intensive care, Mortality

Predicting mortality has been a corner piece of critical care research and practise dating back to the first descriptions of the Acute Physiology and Chronic Health Evaluation score in 1981 [1]. With an increasing burden of non-communicable disease in modern society, preexisting functional status seems to an important contributor to outcome prediction. Poor physical function is an important predictor of mortality in ambulant diseases. The construct of frailty [2], translated from older patient care into critical care, has provided a useful language to discuss pre-morbid functional status.

Whilst frailty can be established from history taking or hospital coding, both of these methods have clinical and research methodological disadvantages. Wilhelmus et al. [3] now offer an alternative approach in a retrospective analysis of computerized tomography scans. Muscle quality as defined by Hounsfield units at the level of L3 was investigated in 491 patients, with a threshold set to define intramuscular adipose tissue and visceral adipose tissue. Higher skeletal muscle density (i.e. better quality) was associated with lower 6-month mortality and shorter hospital length of stay after correction for muscle mass and severity of illness.

Skeletal muscle quality is recognized as a marker of function in healthy individuals [4] and critically ill patients [5]. Alterations are seen with aging [4], immobilization [6], chronic disease states [7] and critical illness [8]. These conditions demonstrate qualitative changes in muscle

\footnotetext{
* Correspondence: Zudin.puthucheary.09@ucl.ac.uk

${ }^{1}$ Institute of Sports and Exercise Health, University College London Hospitals, 1st Floor, 170 Tottenham Court Road, London W1T 7HA, UK

${ }^{2}$ Division of Critical Care, University College London Hospitals, London, UK Full list of author information is available at the end of the article
}

structure as a result of increasing collagen and lipid deposition [6]. Intramyocellular lipid accumulation is additionally a hallmark of metabolic diseases, and may exacerbate tissue metabolic derangements in the critically ill.

A limitation of these data is the inability to relate either chronic disease states and poor muscle quality, or muscle quality and functional outcomes. However, decreased skeletal muscle density as an independent predictor of mortality raises the possibility of its use in multi-dimensional scoring systems such as the NUTRIC score [9] or as an alternative marker of chronic poor physiological reserve in the APACHE system.

A number of key roles for early trajectory assessments exist. First, novel early outcome predictors are needed to guide patient and family expectations and decisionmaking. These need to not only predict risk of death, but also disability, so a patient's wishes may be honoured and a realistic appraisal of functional outcomes can be made. It is vital we improve upon our ability to inform patients and families early in critical illness on the likelihood of significant morbidity. It is possible that admission skeletal muscle quality and quantity may be key to this discussion in the future. Ongoing testing via lean body mass ultrasound [8] and other modalities [10] may also be vital to continued discussions of prognosis. Second, these tests of muscle quality should assist in guiding therapy. A recent post-ICU recovery consensus conference indicated that a major gap exists in understanding how to effectively and efficiently screen patients for specific post-ICU impairments to determine the need for further diagnostic work-up and treatment [11]. Thirdly, the current controversy around personalizing 
nutrition delivery in the ICU to optimize outcome [12] has begun to be addressed by early studies validating the role of the aforementioned NUTRIC score in nutrition risk prediction [9]. High malnutrition risk patients may benefit to a greater degree than those with lower risk. A key addition to this prediction of nutrition risk may be muscle quantity and quality at ICU admission. The ability of the muscle to utilize substrate such as lipid and overall glycogen content [10] may be key in delivering personalized nutrition to improve outcomes. Patients with low muscle quality and quantity may have greater and different specific nutritional requirements. Conversely, increased muscle myosteatosis as defined by decreased skeletal muscle density or increased intermuscular adipose tissue may indicate impaired muscle substrate utilization as implied by Wilhelmus et al. [3]. This may indicate that nutrition delivery needs to account for impaired substrate (lipid) utilization and/or measures need to be taken to improve muscle lipid uptake/utilization (e.g. carnitine [13]). Finally, exercise and reduction of immobility are essential to reduce impaired muscle substrate metabolism and thus improve poor muscle quality.

These assessments may be a key innovation prior to major surgery or cancer therapy. Patients with poor skeletal muscle quality could then be enrolled in prehabilitative exercise/nutrition programmes to improve skeletal muscle quality and quantity [14]. Clinical trials systematically evaluating muscle quality and quantity measures via CT scan and ultrasound could then be performed to assess interventions and target ideal methods to optimize patients. Further, in the ICU, these techniques need further study to determine the muscle-level effects of individual nutrition (e.g. protein delivery, anabolic agents [10]) and specific ICU-rehabilitation interventions (e.g. in-bed ergometry, functional electrical stimulation [15]). Current functional testing (i.e. Medical Research Council sum score, hand-grip strength, walk testing) is both volitional and not muscle specific, and has significant implementation, interpretation and compliance challenges. Thus, the role of muscle quality and quantity measurement described here deserves additional study and validation to add an additional "dimension" to our prediction of outcome and personalization of care in the ICU.

\section{Abbreviations}

APACHE: Acute Physiology and Chronic Health Evaluation; CT: Computerized Tomography; ICU: Intensive care unit; NUTRIC: Nutrition Risk in Critically III

\section{Acknowledgements}

None.

Funding

Not applicable.

Availability of data and materials Not applicable.
Authors' contributions

Both authors contributed equally. Both authors read and approved the final manuscript.

\section{Authors' information \\ See Authors' contributions.}

\section{Competing interests}

The authors declare that they have no competing interests.

\section{Consent for publication}

Not applicable.

\section{Ethics approval and consent to participate}

Not applicable.

\section{Author details}

'Institute of Sports and Exercise Health, University College London Hospitals, 1st Floor, 170 Tottenham Court Road, London W1T 7HA, UK. ${ }^{2}$ Division of Critical Care, University College London Hospitals, London, UK. ${ }^{3}$ Department of Anesthesiology, Duke University of Medicine, Durham, USA. ${ }^{4}$ Duke Clinical Research Institute, Duke University of Medicine, Durham, USA.

Published online: 30 January 2017

References

1. Knaus WA, Zimmerman JE, Wagner DP, et al. APACHE-acute physiology and chronic health evaluation: a physiologically based classification system. Crit Care Med. 1981;9(8):591-7.

2. Bagshaw $S M, M c D e r m i d ~ R C$. The role of frailty in outcomes from critical illness. Curr Opin Crit Care. 2013;19(5):496-503.

3. Wilhelmus GPM, Looijaard IMD, Stapel SN, Girbes ARJ, Twisk JWR, Oudemans-van Straaten HM, Weijs PJM. Skeletal muscle quality as assessed by CT-derived skeletal muscle density is associated with 6 -month mortality in mechanically ventilated critically ill patients. Crit Care. 2016.

4. Watanabe $Y$, Yamada Y, Fukumoto $Y$, et al. Echo intensity obtained from ultrasonography images reflecting muscle strength in elderly men. Clin Interv Aging. 2013;8:993-8.

5. Parry SM, El-Ansary D, Cartwright MS, et al. Ultrasonography in the intensive care setting can be used to detect changes in the quality and quantity of muscle and is related to muscle strength and function. J Crit Care. 2015; 30(5):1151. e9-51 e14.

6. Parry SM, Puthucheary ZA. The impact of extended bed rest on the musculoskeletal system in the critical care environment. Extrem Physiol Med. 2015;4:16.

7. McNelly AS, Rawal J, Shrikrishna D, et al. An exploratory study of long-term outcome measures in critical illness survivors: construct validity of physical activity, frailty, and health-related quality of life measures. Crit Care Med. 2016:44(6):e362-369.

8. Puthucheary ZA, Phadke R, Rawal J, et al. Qualitative ultrasound in acute critical illness muscle wasting. Crit Care Med. 2015:43(8):1603-11.

9. Rahman A, Hasan RM, Agarwala R, et al. Identifying critically-ill patients who will benefit most from nutritional therapy: further validation of the "modified NUTRIC" nutritional risk assessment tool. Clin Nutr. 2016;35(1):158-62.

10. Wischmeyer PE, San-Millan I. Winning the war against ICU-acquired weakness: new innovations in nutrition and exercise physiology. Crit Care. 2015;19 Suppl 3:56.

11. Needham DM, Davidson J, Cohen H, et al. Improving long-term outcomes after discharge from intensive care unit: report from a stakeholders' conference. Crit Care Med. 2012:40(2):502-9.

12. Wischmeyer PE. Are we creating survivors ... or victims in critical care? Delivering targeted nutrition to improve outcomes. Curr Opin Crit Care. 2016;22(4):279-84

13. Bonafe L, Berger MM, Que YA, et al. Carnitine deficiency in chronic critical illness. Curr Opin Clin Nutr Metab Care. 2014;17(2):200-9.

14. Carli F, Minnella EM. Preoperative functional assessment and optimization in surgical patient. Changing the paradigm. Minerva Anestesiol. 2016. [Epub ahead of print].

15. Parry SM, Berney S, Warrillow S, et al. Functional electrical stimulation with cycling in the critically ill: a pilot case-matched control study. J Crit Care. 2014;29(4):695. e1-7. 